\title{
The Interdependence of Mental Health Service Systems: The Effects of VA Mental Health Funding on Veterans' Use of State Mental Health Inpatient Facilities
}

\author{
Rani A. Desai* and Robert A. Rosenheck
}

Northeast Program Evaluation Center, West Haven VAMC, and Department of Psychiatry, Yale University School of Medicine, West Haven, CT, USA

\begin{abstract}
Background: There are relatively few published data on how the financial structures of different health systems affect each other. With increasing financial restrictions in both public and private healthcare systems, it is important to understand how changes in one system (e.g. VA mental healthcare) affect utilization of other systems (e.g. state hospitals).

Aims of Study: This study utilizes data from state hospitals in eight states to examine the relationship of VA per capita mental health funding and state per capita mental health expenditures to veterans' use of state hospitals, adjusting for other determinants of utilization.

Methods: This study utilized a large database that included records from all male inpatient admissions to state hospitals between 1984 and 1989 in eight states $(n=152541)$. Funding levels for state hospitals and VA mental health systems were examined as alternative enabling factors for veterans' use of state hospital care. Logistic regression models were adjusted for other determinants of utilization such as socio-economic status, diagnosis, travel distances to VA and non-VA facilities and the proportion of veterans in the population.

Results: The single strongest predictor of whether a state hospital patient would be a veteran was the level of VA mental healthcare funding $(\mathrm{OR}=0.81$ per $\$ 10$ of funding per veteran in the population, $p=0.0001$ ), with higher VA funding associated with less use of state hospitals by veterans. Higher per capita state funding, reciprocally, increased veterans' use of state hospitals. We also calculated elasticities for state hospital use with respect to VA mental healthcare funding and with respect to state hospital per capita funding. A $50 \%$ increase in VA per capita mental health spending was associated with a $30 \%$ decrease in veterans' use of state hospitals (elasticity of -0.6 ). Conversely, a $50 \%$ increase in state hospital per capita funding was associated with only an $11 \%$ increase in veterans' use of state hospitals (elasticity of 0.06).

Implications for Health Care Provision and Use: These data indicate that per capita funding for state hospitals and VA mental health systems exerts a significant influence on service use, apparently mediated by the effect on supply of mental health services. Veterans are likely to substitute state hospital care for
\end{abstract}

*Correspondence to: Rani Desai, NEPEC/182, VA Connecticut Health Care System, 950 Campbell Avenue, West Haven, CT 06516, USA. Email address: desai@biomed.med.yale.edu

Source of funding: This study was indirectly funded through the Department of Veterans Affairs, through which both authors are employed.
VA care when funding restrictions limit the availability of VA mental health services. However, due to the relative sizes of the two systems, VA funding has a larger effect than state hospital funding upon state hospital use by veterans.

Implications for Health Policies: These data indicate that changes in the organizational and/or financial structure of any given healthcare system have the potential to affect surrounding systems, possibly quite substantially. Policy makers should take this into account when making decisions, instead of approaching systems as independent, as has been traditional.

Implications for Further Research: Further research is needed in two areas. First, these results should be replicated in other systems of care using more recent data. Second, these results are difficult to generalize to individual behavior. Future research should examine the extent and individual determinants of cross-system use. Copyright (C) 2000 John Wiley \& Sons, Ltd.

Received 26 August 1999; accepted 5 May 2000

\section{Introduction}

With the advent of managed mental health care, and continuing restrictions placed upon mental health services provided in the public sector, researchers have begun to examine the consequences of changes in access, quality, and outcomes of care, especially for vulnerable people such as those with serious mental illnesses. Populations such as people with disabling mental illnesses may face increasing difficulty obtaining access to needed mental health treatment, may be faced with a more restricted range of available treatment options and may experience the double disadvantage of both having limited financial resources and often needing high intensity care. ${ }^{1}$

While the overall restriction of available services in a single system of care may result in certain patients simply not receiving the care that they need, some patients may successfully negotiate entrance to other systems of health care. Data from a study of a large private corporation found that as restrictions on use of mental health care increased, use of medical services and sick days increased among mental health patients. ${ }^{2}$ Another recent study based upon national surveys of mental health programs and providers found that two-thirds of facilities that provided inpatient 
psychiatric care had transferred patients to other systems of care when their insurance benefits were exhausted. ${ }^{3}$ However, no information was available on the frequency of these transfers, or the effects of such transfers upon clinical outcomes or overall mental health utilization.

The Department of Veterans Affairs (VA) healthcare system provides a unique opportunity to study the effects of funding for mental health services on utilization of other systems of care. All veterans with a service-connected disability or low income are eligible to receive a full range of physical and mental healthcare services from VA health care facilities. Most veterans are aware of the VA healthcare system, ${ }^{4}$ but only a modest proportion (30\% of those who are eligible) actually use VA health services annually. ${ }^{5}$ It has been presumed that many of these patients, who would not have the resources to access private psychiatric care, might receive their mental health care from state-funded programs such as community mental health centers and state psychiatric hospitals. However, this has not been empirically tested.

In general, there are very few data on out-of-system use of mental health services, partially due to the difficulty in collecting exhaustive and reliable mental health utilization data from multiple systems. A previous study conducted among veterans who utilized VA mental health services examined the factors that predicted the use of non-VA services in the previous six months. That study found that $23 \%$ of VA mental health outpatients had also used nonVA services in the previous six months. Factors that significantly predicted non-VA use were a diagnosis other than schizophrenia, not having a service-connected disability, and being female. ${ }^{5}$

There are also few data on how systems that provide similar services in the same geographic area affect each other. One study conducted with VA mental health service use data indicates that the level of funding for VA mental health care, and the efficiency with which that care is delivered, are both significant predictors of VA health service utilization, accounting for about $7 \%$ of the variance. ${ }^{6}$ In addition, there appeared to be substitution of State mental health services for VA services when state funding was higher. However, that study did not have detailed diagnostic data on individual patients, and had to rely on aggregate measures of disability in the population.

In this study we approach the issue of cross-system use by examining the proportion of patients being treated in state mental health inpatient facilities who are veterans, and the effects of levels of VA and non-VA funding on the likelihood that veterans use state mental hospitals. We use the Anderson-Newman model of healthcare utilization, ${ }^{7}$ proposing that there are three sets of factors that predict whether an individual will utilize health services: predisposing factors, need factors and enabling factors. Predisposing factors are those individual characteristics that affect the background likelihood of health services utilization without directly impacting a person's capability of obtaining care. Such factors include race/ethnicity, gender, and religious affiliation. Need factors, the set of factors that are consistently the most important determinants of utilization, ${ }^{8}$ include those objective and subjective states of distress that lead to the perceived need for services. Finally, enabling factors are those environmental and individual characteristics that create an environment in which individuals are able to access care. Such factors include eligibility for services, the supply and cost of services and geographic distance to services. They can also include the level of funding available for mental health services in two or more alternative service systems.

\section{Methods}

\section{Sources of Data}

Data for this study were taken from a large collaborative project initiated by the Division of Biometry and Applied Science, National Institute of Mental Health. The data were collected from 1984 through 1989, and were compiled by the National Association of State Mental Health Program Directors (NASMHPD) with funding from the Center for Mental Health Services. This longitudinal database was designed to compile and report data on patients treated in public mental health service systems. The project took advantage of existing administrative data at each state facility that participated in the project, standardized data reporting and formats across facilities, and compiled all data into a single repository for use in mental health services research. ${ }^{9}$

The database contains information on each episode of care provided in each state mental hospital in each of the participating states between 1984 and 1989. There were 13 required data fields for each episode of care, and 42 additional optional items that were submitted if available. The sample utilized in these analyses includes only the first episode of care for adult males treated during the data abstraction period in states that reported veteran status (an optional item in the database). Additionally, each patient in the sample had to have a primary mental health or substance abuse diagnosis. Patients diagnosed with dementia, cognitive impairment, mental retardation or autism were excluded. There were 152541 males from eight states included in these analyses. Only males are included since the majority $(95 \%)$ of veterans are male.

\section{Variables of Interest}

The dependent variable of interest was a bivariate variable representing veteran status. Because this was not a required field for the database, only the eight states that recorded veteran status in their administrative data routinely were included. These were Missouri, New York, Ohio, Oklahoma, Tennessee, Vermont, Virginia and the state of Washington (not the city of Washington, District of Columbia).

The primary independent variables of interest included the annual State Mental Hospital and VA per capita mental health expenditures. Other variables were added to models to adjust for potential confounding and included race, marital status and age (predisposing factors); primary diagnosis at 
the time of discharge from the hospital (need factor) and distance from residence to the nearest VA and non-VA facility (enabling factor). In addition, several census level variables were added to multivariate models to adjust for the distribution of eligible veterans across counties in each state. These included the proportion of veterans among men living in the county of residence and the proportion of veterans in the county who were eligible for VA services due to low income or disability.

State mental health agency expenditures per capita were calculated by dividing total State hospital expenditures in each state $^{10}$ by the adult state population. ${ }^{11}$ VA mental health expenditures per veteran in the population were calculated using the VA Cost Distribution Report, which summarizes expenditures by VA for various healthcare programs in each state, and dividing by the total number of veterans in the population of each state (using census data).

Predisposing and need factors were all taken directly from the required database fields of the longitudinal database. Primary diagnosis was coded as DSM-III-R diagnoses, ${ }^{12}$ and were grouped for these analyses into the following categories: schizophrenia (297-298), bipolar depression (296.4-296.9), other psychosis (291), alcoholism (291, 303, 305.00-305.06), drug abuse (292, 304, 305.10-305.99), major depression (296.2-296.3, 300.4, 311), anxiety disorders (308-309, 300.00-300.39), personality disorders (301) and other diagnoses $(302,300.6-300.9)$. We chose to use the primary diagnosis at discharge instead of admission since many patients are admitted for evaluation with only a tentative diagnosis that is later revised.

Zip code of residence (a required field in the longitudinal database) was used to calculate the distance to the nearest $\mathrm{VA}$ and non-VA facility because this is a powerful predictor of VA use. ${ }^{5}$ Using mapping software, we calculated the linear distance between the weighted center of the zip code of residence and the nearest VA and non-VA inpatient facility. The proportion of veterans in each county of each state was calculated using age-, gender- and veteran-stratified county census data from each state. The percentages of veterans in each county who had a service-connected disability and who had low incomes were calculated from the Veteran Supplementary Report from the 1990 census.

\section{Data Analytic Procedures}

Analysis proceeded in several steps. First, to determine whether veterans were significantly different from nonveterans in the state system, the sample was divided by veteran status and compared on state of residence, age, race, marital status, diagnosis and distance from residence to the nearest VA and non-VA facility using $t$-tests for continuous variables and chi-square tests for categorical variables.

Second, in order to examine whether veterans were overor under-represented among state hospital patients we calculated, for each state in the data, the age-adjusted proportion of veterans in the state hospital patient population and the age-adjusted proportion of veterans in the general population. Adjustment utilized the age distribution of all males over age 18 in the general population of each state as the standard population.

Third, we compared states on the average proportions of veterans who are eligible for VA services. We calculated, from census data, the average percentage of veterans in the state who had a service-connected disability or low income, both of which give veterans priority in the VA healthcare system.

Finally, we built a logistic regression model that predicted the likelihood that any given male patient in the state hospital was a veteran. We included all predisposing, enabling and need factors in the model. Odds ratios (ORs) were calculated that indicated for each factor whether state hospital patients were more or less likely to be veterans. Odds ratios for continuous variables indicate the change in likelihood of being a veteran per one unit change in the continuous variable.

Due to the nature of the odds ratio, the relative odds of a particular state patient being a veteran is equivalent to the relative odds that a veteran will access state mental health care as compared to a non-veteran. ${ }^{13}$ Standardized estimates of odds ratios were also calculated, allowing a direct comparison of the relative strength of association between various factors.

Because there are individual, county- and state-level variables entered into the same statistical model, hierarchical linear models (HLMs) would be most appropriate for these data. However, the size of the dataset was too large for such models to be fit. To test whether hierarchical structure was likely to have strongly affected results, we took a series of 400 stratified random samples of the data (stratified by state, $n=4000$ each) and fit HLM models to the smaller data sets, finally averaging parameter effects over the 400 HLM models. Since the results did not significantly differ from a logistic regression model (estimate sizes were slightly different, but variance estimators did not change significantly), for ease of presentation we present the logistic regression results.

\section{Results}

Table 1 presents a comparison between veterans and nonveterans on those factors for which we had individual data. Veterans were more likely to be married or previously married than non-veterans $(p=0.001)$, more likely to be white than non-veterans $(p=0.001)$ and significantly older by about ten years $(p=0.0001)$. Veterans were also more likely to have a primary diagnosis of alcoholism or bipolar depression than non-veterans, and were less likely to have a primary diagnosis of schizophrenia or anxiety disorders than non-veterans $(p=0.001)$. Veterans lived farther away from the nearest VA by about six kilometers $(p=0.0001)$, and lived farther away from the nearest non-VA, although only by about one kilometer $(p=0.0001)$.

Tables 2 and 3 present comparisons across states in characteristics of the population and per capita VA mental health and state hospital expenditures. Table $\mathbf{2}$ indicates that the age-adjusted rate of veterans in the state hospital 
Table 1. Description of a sample of state hospital patients in eight states, NASMHPD state data 1984 through 1989

\begin{tabular}{|c|c|c|c|c|c|}
\hline \multirow[b]{2}{*}{ Variable } & \multicolumn{2}{|c|}{ Non-veterans } & \multicolumn{2}{|c|}{ Veterans } & \multirow[t]{2}{*}{$p$} \\
\hline & $n$ & $\%$ & $n$ & $\%$ & \\
\hline \multicolumn{6}{|l|}{ Diagnosis } \\
\hline Schizophrenia & 43364 & 34.62 & 7527 & 31.06 & 0.001 \\
\hline Other psychosis & 8245 & 6.58 & 1147 & 4.73 & \\
\hline Alcoholism & 29025 & 23.18 & 6833 & 28.19 & \\
\hline Drug abuse & 6795 & 5.43 & 1175 & 4.85 & \\
\hline Bipolar depression & 17364 & 13.86 & 4065 & 16.77 & \\
\hline Depression & 3931 & 3.14 & 857 & 3.54 & \\
\hline Anxiety & 13470 & 10.76 & 2125 & 8.77 & \\
\hline Personality disorder & 1949 & 1.56 & 337 & 1.39 & \\
\hline Other & 1098 & 0.88 & 169 & 0.7 & \\
\hline \multicolumn{6}{|l|}{ Marital status } \\
\hline Never married & 88198 & 66.24 & 8865 & 34.62 & 0.001 \\
\hline Married & 17274 & 12.97 & 6025 & 23.53 & \\
\hline Separated/divorced & 27682 & 20.79 & 10714 & 41.85 & \\
\hline \multicolumn{6}{|l|}{ Race } \\
\hline White & 103068 & 67.93 & 21443 & 76.59 & 0.001 \\
\hline Black & 37953 & 25.01 & 5732 & 20.47 & \\
\hline Hispanic & 8029 & 5.29 & 329 & 1.18 & \\
\hline \multirow[t]{2}{*}{ Other } & 2686 & 1.77 & 493 & 1.76 & \\
\hline & Mean & $\mathrm{SD}$ & Mean & SD & \\
\hline Age & 42.99 & 15.21 & 51.15 & 13.8 & 0.0001 \\
\hline Distance from residence to nearest & & & & & \\
\hline VA facility $(\mathrm{km})$ & 28.68 & 32.14 & 34.76 & 34.57 & 0.0001 \\
\hline $\begin{array}{l}\text { Distance from residence to nearest } \\
\text { non-VA }(\mathrm{km})\end{array}$ & 5.86 & 4.63 & 6.53 & 5.17 & 0.0001 \\
\hline
\end{tabular}

Table 2. Age-adjusted proportions of veterans and state expenditures across eight states of the NASMHPD (longitudinal state data) 1984 through 1989

\begin{tabular}{lcccc}
\hline & & & Age-adjusted \% of vets \\
State & $\begin{array}{c}\text { Age-adjusted \% of vets } \\
\text { in the male population }\end{array}$ & $\begin{array}{c}\text { Stat health agency } \\
\text { expenditures per capita } \\
\text { per year (\$) }\end{array}$ & $\begin{array}{c}\text { VA expenditures on } \\
\text { mental health per veteran } \\
\text { per year }(\$)\end{array}$ \\
\hline MO & 21.43 & 32.15 & 33.35 & 70.47 \\
NY & 7.29 & 24.86 & 89.52 & 105.86 \\
OH & 18.81 & 30.96 & 23.79 & 60.32 \\
OK & 27.86 & 32.38 & 20.87 & 33.26 \\
TN & 14.11 & 29.01 & 20.05 & 82.20 \\
VA & 18.39 & 31.39 & 28.61 & 73.89 \\
VT & 24.77 & 29.33 & 19.93 & 72.66 \\
WA & 7.33 & 34.73 & 19.15 & 42.27 \\
\hline
\end{tabular}

patient population differed greatly across states. Oklahoma had the highest proportion of veterans in the state hospital system (27.9\%), and New York had the lowest proportion of veterans $(7.3 \%)$. In contrast, the proportion of veterans in the general male population did not differ greatly across states. However, Oklahoma had the highest proportion of veterans in the population (32.4\%) and New York had the lowest proportion of veterans in the population $(24.9 \%)$.

Table 2 also presents per capita expenditures for the relevant target population in the state hospital and VA mental healthcare systems. The numbers presented in the table represent how much each state hospital system spends per capita per year, and how much the VA spends on mental healthcare per veteran in the population of each state per year. The extremes of state hospital spending were in the states of Washington ( $\$ 19.15$ per capita per year) and New York (\$89.53 per capita per year). In VA spending, costs are highest in New York (\$105.86 per veteran per year) and lowest in Oklahoma ( $\$ 33.26$ per veteran per year).

Table 3 presents the distribution across states of the 
Table 3. Differences across eight states in veteran population, NASMHPD state data 1984 through 1989

\begin{tabular}{lccc}
\hline & $\begin{array}{c}\text { \% of veterans } \\
\text { in state who } \\
\text { are service } \\
\text { connected }\end{array}$ & $\begin{array}{c}\text { \% of veterans } \\
\text { in state who } \\
\text { are low income }\end{array}$ & $\begin{array}{c}\text { Average distance } \\
\text { to nearest VA } \\
(\mathrm{km})\end{array}$ \\
State & 6.72 & 11.91 & 40.62 \\
MO & 7.71 & 8.99 & 20.20 \\
NY & 7.27 & 9.18 & 27.70 \\
OH & 10.61 & 12.66 & 40.52 \\
OK & 7.86 & 11.41 & 37.37 \\
TN & 7.35 & 8.61 & 24.67 \\
VA & 8.84 & 9.16 & 31.19 \\
VT & 8.98 & 9.01 & 46.11 \\
WA & & & \\
\hline
\end{tabular}

These proportions are averaged across every county in the state and weighted by the male veteran population in each county.

proportion of veterans in the population who have priority for receiving VA services. These include those who have a service-connected disability and those who had low incomes (annual household income under \$20000). Here the highest proportions of eligible veterans are found in Oklahoma ( $10.6 \%$ with disability and $12.7 \%$ with low incomes). The average distance to the nearest VA is also highest in Oklahoma $(40.52 \mathrm{~km})$ and lowest in New York $(20.2 \mathrm{~km})$.

Table 4 presents the logistic regression model that predicts the likelihood that a given patient in the state hospital system will be a veteran. Odds ratios indicate, for each variable, how much more likely veterans in the state facility will be to have a particular characteristic than non-veterans.
Veterans were older ( $\mathrm{OR}=1.3$ per ten years, $p=0.0001)$ and more likely to be previously married $(\mathrm{OR}=1.71, p=$ 0.0001). On the other hand, veterans were less likely to be single $(\mathrm{OR}=0.68, p=0.0001)$. Veterans were also less likely than non-veterans to be diagnosed with anxiety disorders. Distance from zip code of residence to the nearest VA and non-VA facilities was not significantly associated with veteran status after adjusting for other factors and accounting for the large sample size $(\mathrm{OR}=1.01$ per $16 \mathrm{~km}$, $p=0.0367)$. Finally, veterans who live in counties with a higher concentration of service-connected veterans, who have priority access to VA services, are significantly less likely to access State hospitals $(\mathrm{OR}=0.95, p=0.0001)$.

Finally, Table 4 presents the effect of funding on the proportion of veterans in state hospitals. The more each state spends on mental health care, the more likely a male patient in a state hospital is to be a veteran $(\mathrm{OR}=1.02$ per dollar increase in per capita spending, $p=0.0018)$. Conversely, the more VA spends per veteran on mental health care the less likely a state hospital patient is to be a veteran $(\mathrm{OR}=0.81$ per dollar increase in VA spending, $p$ $=0.0001)$. In fact, VA expenditures are the strongest predictor of whether a state hospital patient will be a veteran, as indicated by the standardized estimates ( standardized estimate $=-0.29$ ).

\section{Discussion}

These analyses indicate that the levels of funding for mental health care in the state hospital and VA systems have a significant impact on utilization of state mental healthcare

Table 4. Logistic regression model predicting the probability that a state Hospital patient is a veteran, NASMHPD state data 1984 through 1989

\begin{tabular}{|c|c|c|c|}
\hline Variable & OR & $\begin{array}{l}\text { Standardized } \\
\text { estimate }\end{array}$ & $p$ \\
\hline Age in years (per 10 years) & 1.30 & 0.23 & 0.0001 \\
\hline \multicolumn{4}{|l|}{ Race (ref.: white) } \\
\hline Black & 0.97 & -0.01 & 0.1156 \\
\hline Hispanic & 0.42 & -0.1 & 0.0001 \\
\hline Other & 0.71 & -0.02 & 0.0001 \\
\hline \multicolumn{4}{|l|}{ Marital Status (ref.: married) } \\
\hline Single & 0.68 & -0.11 & 0.0001 \\
\hline Separated/divorced & 1.71 & 0.12 & 0.0001 \\
\hline \multicolumn{4}{|l|}{ Diagnosis (ref.: anxiety disorders) } \\
\hline Alcohol & 1.62 & 0.11 & 0.0001 \\
\hline Drug abuse & 1.17 & 0.02 & 0.0001 \\
\hline Bipolar & 1.51 & 0.07 & 0.0001 \\
\hline Schizophrenia & 1.33 & 0.07 & 0.0001 \\
\hline Other psychosis & 1.03 & 0.003 & 0.4315 \\
\hline Depression & 1.44 & 0.03 & 0.0001 \\
\hline Personality disorder & 1.29 & 0.02 & 0.0002 \\
\hline Other & 0.73 & -0.01 & 0.0005 \\
\hline Distance to VA (per $16 \mathrm{~km}$ ) & 1.01 & 0.01 & 0.0367 \\
\hline Distance to non-VA (per $16 \mathrm{~km}$ ) & 0.99 & -0.001 & 0.7391 \\
\hline Proportion of county that is a veteran (per $10 \%)$ & 1.33 & 0.09 & 0.0001 \\
\hline$\%$ of veterans in county who are service-connected & 0.95 & -0.05 & 0.0001 \\
\hline$\%$ of veterans in county who are low income & 1.01 & 0.01 & 0.0087 \\
\hline VA mental health expenditures per veteran (per $\$ 10$ ) & 0.81 & -0.29 & 0.0001 \\
\hline State mental health agency expenditures per capita (per \$10) & 1.02 & 0.04 & 0.0018 \\
\hline
\end{tabular}


by veterans, even after adjusting for other determinants of utilization.

In principal, higher expenditures on mental healthcare need not translate into higher availability, or utilization, of mental health services if care is delivered inefficiently. However, data from the national VA mental health monitoring system indicate that in 1998 the total VA mental health expenditures per eligible veteran in the population was correlated at 0.30 with the proportion of eligible veterans who were seen in VA mental health programs. ${ }^{14}$ These analyses suggest that the higher availability of VA mental health services does in fact decrease the likelihood that veterans will use state hospitals. Taking New York and Oklahoma as two extreme examples, New York VA hospitals spent the most per veteran on mental health care and had the lowest proportion of veterans in state facilities, while the Oklahoma VA system spent the least per veteran and had the highest proportion of veterans in the state system.

One way to approach the interdependence of systems is to examine the elasticity of state mental health facility use with respect to local VA funding levels (elasticity is the expected decrease in the probability of a veteran accessing state hospital for every percentage increase in VA mental health spending). In the case of these data, the parameter estimate for the logistic regression model indicates that for every $\$ 10$ increase in VA spending the odds of a state hospital patient being a veteran goes down. At the mean VA spending level, which is $\$ 34$ per veteran, the fitted likelihood of being a veteran in the state hospital is calculated at $5.28 \%$. If the VA funding level were to increase by $50 \%$, to $\$ 51$ per veteran, the probability of being a veteran in the state hospital drops to $3.72 \%$, a $30 \%$ decrease. Thus, a $50 \%$ increase in spending by VA would be expected to lead to a $30 \%$ decrease in veterans treated in state hospitals, for an elasticity of -0.6 . Furthermore, this effect is not linear, so that a greater decrease in non-VA use would be expected if VA funding levels started out lower, and a smaller change would be seen if VA funding was already at higher levels.

Conversely, the level of state hospital funding has a much smaller, but positive, effect upon veterans' use of state hospitals. At $\$ 32$, the average per capita expenditure for mental healthcare in the state hospitals, the fitted probability of a veteran using the state hospital is $11.01 \%$. If the funding were to increase by $50 \%$ to $\$ 48$, the probability increases only slightly to $11.3 \%$, for an elasticity of 0.06 . Thus, the elasticity of VA funding and veterans' access to state hospitals is much higher than the elasticity of state funding and veterans' access to state hospitals.

The striking difference could be explained by the fact that the VA system represents only a small proportion of the total mental healthcare provided by government agencies in each state. For example, while total (inpatient and outpatient) state mental health expenditures in 1988 for all 50 states was about 7 billion dollars ( $84 \%$ of total state and VA mental health spending), total VA mental health expenditures totaled only 1.3 billion ( $16 \%$ of total state and VA mental health spending ${ }^{11}$. It could also be explained by the fact that veterans must compete with other, non- veteran, mentally ill patients for state services, while the VA offers services exclusively to veterans. Thus, a given increase in state funding would have less effect upon veterans' utilization of state hospitals than a corresponding increase in VA funding.

While these elasticities indicate that the two systems are indeed interdependent, this does not necessarily imply a need for changes in current funding structures in either of the two systems. The VA system was designed to offer federally funded health care services to a sector of the population that is a special national responsibility, but veterans are also citizens of the state in which they reside, and as such are fully eligible to receive state services as well. The VA system relieves some financial pressure on the state by treating a portion of the population outside of the state system, but would not be expected to replace the state hospital system for all veterans.

The implication for the international community of these data apply even to those nations with universal health care coverage. In any large system of healthcare there are limited resources, and those resources must be allocated in some organized fashion, whether it be by geographic area or individual facility. These data indicate that changes in resource allocation, which can have an effect on supply of services in a given geographic area, can thereby affect patients accessing care even when they cannot change systems of care. Such patients in areas with reductions in supply may be more likely to go without care, or find ways to supplement their benefits with out-of-pocket expenditures.

\section{Limitations}

Although these results highlight some important system characteristics that affect veterans' use of state hospitals, several important limitations deserve comment. First, these data are all based on administrative records, with the expected reporting errors and omissions common to such data. In particular, veteran status was not a required field for these data, and many states did not report veteran status at all. In addition, even among those states that did report veteran status, it is unknown how accurate the data arehowever, it is most likely that veteran status was underreported, leading to probable underestimation of effects.

Second, the large sample size in these analyses is a limitation because it resulted in a number of variables being highly statistically significant with only small effect sizes. We addressed this issue by reducing the required alpha level for statistical significance.

Third, these analyses only examine the cross-sectional characteristics of one system. In counties with high concentrations of veterans who would be eligible for VA mental health care, it is unknown if the lower proportions of veterans in the state system is a direct result of higher VA utilization or an overall reduction in mental health utilization among veterans. Without complete data from multiple systems of care, we cannot tell whether there is crosssystem substitution of services, or whether certain populations are not receiving care at all. 
Finally, these data were collected from 1984 through 1989, and both VA and state hospital systems have undergone substantial changes since that time. These changes have included the advent of managed care practices in many state systems, and the closing of $80 \%$ of VA inpatient mental health beds in 1996. However, the available data on the interdependence of healthcare systems are so scarce that even older data will be valuable: these data can serve as a useful baseline against which to compare changes, and with shrinking financial resources the effects found in these analyses would likely be strengthened in more recent data. Future research should examine these trends in light of the impact of managed care on public mental healthcare.

\section{Future Research}

These data indicate that, at least at the state population level, VA and state mental health systems are interdependent and may serve as substitutes, albeit imperfect substitutes, for each other. There are two further avenues of research that should be pursued. First, these data were collected in the latter half of the 1980s, and in the mid-1990s the VA underwent a major restructuring. One effect of that restructuring was that priority funds were shifted from the Northeast (e.g. New York) to the Southwest (e.g. Arizona). This shift in funding may have had an effect upon the local state mental health agencies in the Northeast as VA facilities have closed inpatient beds and generally reduced mental health funding, and it should be possible to examine movement from VA to non-VA care in these states.

Second, it is difficult to generalize these findings to individuals. Although at the state population level the two systems may substitute for each other, this may not necessarily be true at the level of the individual deciding where to seek treatment. Further research is needed to examine the patterns of cross-system use, the determinants of that use and those individual and system-level factors that affect the volume of cross-system use.

\section{References}

1. Leslie DL, Rosenheck RA. Shifting from inpatient to outpatient care? Mental health utilization and costs in a privately insured population. Am J Psychiatry 1999; 156 (8): 1250-1257.

2. Rosenheck RA, Druss BG, Stolar M, Leslie DL, Sledge W. Effect of declining mental health service use among employees of a large self-insured private corporation. Health Affairs 1999; Sept-Oct; 180 (5): 193-203.

3. Schlesinger M, Dorwart $\mathrm{R}$, Hoover $\mathrm{C}$ et al. The determinants of dumping: a national study of economically motivated transfers involving mental health care. Health Services Res; 1997; 32 (5): 561-590.

4. Hoff RA, Rosenheck RA. Female veterans' use of Department of Veterans Affairs health care services. Med Care; 1998; 36 (7): 1114-1119.

5. Hoff RA, Rosenheck RA. Cross-system service use among psychiatric patients: data from the Department of Veterans Affairs. J Behav Health Services Res; 2000 Feb; 27 (1): 98-106.

6. Rosenheck RA, Stolar M. Access to public mental health services: determinants of population coverage. Med Care; 1998; 36 (4): 503-512.

7. Anderson RF, Newman JF. Societal and individual determinants of medical care utilization in the United States. Millbank $Q$ 1973; 51: 8.

8. Leaf PJ, Bruce ML. Gender differences in the use of mental healthrelated services: a re-examination. J Health Soc Behav 1987; 28 (June): 171-183.

9. Altaffer F, Athearn T, White C. Data Definitions and Techniques of Measurement for the Collaborative Project on the Longitudinal Data Base of Inpatient Episodes in State Psychiatric Hospitals. Alexandria, VA: NASMHPD Research Institute, 1995.

10. Center for Mental Health Services and National Institute of Mental Health. Mental Health, United States, 1992, DHHS Publication No. (SMA)92-1942, Manderscheid RW, Sonnenschein MA (eds). Washington, DC: Supt. of Docs., US Government Printing Office, 1992.

11. United States Census Bureau. 1990 Census.

12. American Psychiatric Association (APA). The Diagnostic and Statistical Manual for Mental Disorders, 3rd edn. Washington, DC: APA, 1989.

13. Schlesselman JJ. Case-Control Studies: Design, Conduct, Analysis. Oxford University Press: New York, 1982.

14. Rosenheck RA. National Mental Health Program Performance Monitoring System: Fiscal Year 1998 Report. West Haven: Northeast Program Evaluation Center, 1999. 